\title{
Effect of Weight Reduction Following Bariatric Surgery on Serum Visfatin and Adiponectin Levels in Morbidly Obese Subjects
}

\author{
Mohammad Javad Hosseinzadeh-Attar ${ }^{a} \quad$ Atefeh Golpaie $^{a} \quad$ Leila Janani $^{b}$ \\ Hoda Derakhshanian ${ }^{a}$ \\ ${ }^{a}$ Department of Nutrition and Biochemistry, ${ }^{b}$ Epidemiology and Biostatistics Department, \\ School of Public Health, Tehran University of Medical Sciences, Tehran, Iran
}

\author{
Key Words \\ Adiponectin · Visfatin · Morbid obesity · Bariatric surgery · Weight loss
}

\begin{abstract}
Objective: Adipokines are signaling and mediator proteins secreted from adipose tissue. A novel adipokine, visfatin, was reported as a protein which was mainly expressed in visceral adipose tissue. Controversial results have been shown regarding the changes of adipokines following weight reduction. So we investigated the effects of weight reduction on serum concentrations of adiponectin and visfatin in morbidly obese subjects. Methods: 35 severely obese patients ( 26 females and 9 males), aged $15-58$ years, were studied. Anthropometric parameters and biochemical parameters as well as adiponectin and visfatin were analyzed before and 6 weeks after weight reduction. Results: Anthropometric indices decreased significantly. Blood levels of low-density lipoprotein cholesterol, high-density lipoprotein cholesterol, and triglyceride were reduced significantly. The reduction of visfatin and the elevation of adiponectin were significant as well. However, other parameters like fasting glucose and insulin did not change. Moreover, we could not find any significant correlation between the change of serum visfatin and that of adiponectin. Conclusions: 6 -week weight reduction after bariatric surgery resulted in decreased serum visfatin and increased adiponectin levels. However, we cannot find any significant correlation between changes of adiponectin, visfatin, BMI, waist circumference, and insulin resistance. Further studies with different design are suggested to clarify these associations.


Hosseinzadeh-Attar et al.: Effect of Weight Reduction Following Bariatric Surgery on Serum Visfatin and Adiponectin Levels in Morbidly Obese Subjects

\section{Introduction}

It has been widely confirmed that obesity is a major cause of morbidity and mortality. Obesity as a chronic low-grade inflammatory state is associated with many disorders such as diabetes mellitus, cardiovascular disease, and atherosclerosis $[1,2]$. The exact mechanism linking obesity with these complications has not been elucidated $[3,4]$.

Recent studies suggested that bariatric surgery interventions had increased in morbidly obese patients because of more successful weight loss, longer-term weight maintenance, and enhancement of health-related quality of life [5]. A number of reports showed that bariatric surgery was associated with a notable reduction of all-cause mortality. Also comorbid conditions, including diabetes, hypertension, dyslipidemia and insulin resistance, have been improved [6]. Therefore, this method may be considered as a favorable option for treatment of morbidly obese patients. However, further studies are needed to elucidate the mechanisms resulting in decreased mortality among these patients after bariatric surgery [7].

It has been shown that adipose tissue has an important endocrine function under physiological and pathophysiological conditions [8-10]. Adipokines which are secreted from white adipose tissue could explain at least a part of the pathologic changes accompanying obesity [11]. The metabolism of almost all known adipokines is markedly dysregulated in obesity. The serum levels of most of them are increased, others, like adiponectin, are decreased [11, 12].

Visfatin (pre-B-cell colony enhancing factor) was previously described as a modulator of B-cell differentiation. It is also recognized in lymphocytes, bone marrow, muscle, and liver [13].However, visfatin has recently been identified as a new adipokine which is produced mainly by visceral adipose tissue [14] and is involved in the process of glucose metabolism and inflammation $[15,16]$. It has been shown that visfatin exerts insulin-mimetic effects and stimulates glucose utilization in peripheral tissues $[14,17,18]$. However, its biological role and the underlying mechanisms are not entirely clear yet. It is hypnotized that visfatin secretion could be a compensatory mechanism or part of the pathophysiology of diabetes [19]. In fact, the relationship between visfatin and diabetes or insulin resistance was not clear, and the results of different studies were inconsistent $[20,21]$. Thus further studies are needed to clarify the role of visfatin in insulin resistance and related metabolic disorders [22]. Previous studies showed inconsistent results regarding changes of serum visfatin levels in obesity and metabolic syndrome; both increasing and decreasing [14, 21, 23-27] and even unchanged $[28,29]$ levels of visfatin had been found. The observed changes of visfatin levels after bariatric surgery and weight reduction were also inconsistent [21, 30, 31]. In some of these studies the serum levels of this adipokine actually remained unchanged [31]. In addition, many studies suggested that this adipokine is related to inflammation in obesity via different mechanisms [32]. With these conflicting results in mind, it remains a matter of ongoing discussion whether or not there is an association between obesity, weight reduction and serum visfatin concentrations [33].

Further studies investigated if there is any difference in the visfatin mRNA expression of visceral (VAT) and subcutaneous adipose tissue (SAT) in lean and obese individuals. Berndt et al. [34] found a positive correlation between visfatin mRNA expression of VAT, BMI and \%body fat. Moreover, they found a negative correlation between BMI and visfatin expression of SAT. Pagano et al. [25] indicated that visfatin mRNA expression was lower in SAT and higher in VAT of obese than of lean individuals. Varma et al. [20] also found a positive correlation between BMI and visfatin gene expression in VAT and a negative correlation between BMI and visfatin gene expression in SAT.

Adiponectin, another adipokine which is secreted from adipocytes, has anti-inflammatory and anti-atherogenic effects [35] by suppressing pro-inflammatory cytokines such as 
TNF- $\alpha$ and inducing other anti-inflammatory factors [36]. Many studies showed that the adiponectin level is lower in the insulin-resistant stage and increased with improved insulin sensitivity after weight loss $[12,37,38]$. In vivo studies demonstrated that adiponectin enhanced the energy consumption and fatty acid oxidation in the liver and muscles, resulting in a decrease of the tissue triglycerides and an improvement of insulin sensitivity [39].

It has been suggested that weight loss is accompanied by changes in the inflammatory state and adipokine levels. However, the changes of inflammatory and anti-inflammatory adipokines during short-term and rapid weight loss in young morbid obese subjects are not exactly understood, and conflicting results have been reported [40]. So the aim of our study was to evaluate the changes in circulating visfatin and adiponectin levels following weight loss in morbidly obese subjects and whether or not there are associated changes of other metabolic parameters.

\section{Material and Methods}

35 morbidly obese subjects ( 26 females and 9 males), aged $33.5 \pm 9.1$ years (range 15-58 years), were recruited to study the changes of adiponectin and visfatin levels after bariatric surgery at university hospitals. These patients received bariatric surgery after failure of other weight loss strategies. Patients were treated by laparoscopic gastric banding (LAGB), laparoscopic total gastric vertical plication (LTGVP), or gastric bypass according to the evaluation and choice of the surgeon.

Subjects with the following conditions were excluded from the study: presence of type 2 diabetes mellitus or use of antiglycemic medications (metformin, thiazolidinediones, insulin), hypo- or hyperthyroidism, hypertension and/or use of anti-hypertensive drugs, ischemic heart disease or stroke, any malignancy, chronic kidney or liver disease, obesity caused by an endocrine disorder, Cushing syndrome, psychiatric disorders, pregnancy or lactating, rheumatoid arthritis, smoking and alcohol intake, and use of lipidlowering medications (statins, fibrates). The study protocol was approved by the ethics committee of the university, and all subjects signed written informed consent.

\section{Study Protocol}

Patients underwent a clinical assessment including medical history, physical examination and co-morbidity evaluation by a multidisciplinary consultation team and anthropometric measurement; fasting blood samples were collected prior to and 6 weeks after surgery.

\section{Measurements of Anthropometric Indices and Blood Pressure}

Anthropometric indices and blood pressure were measured prior to, and 6 weeks after surgery by using standard methods. Body weight was measured to the nearest $0.1 \mathrm{~kg}$ using a calibrated manual weighing scale (Seca 709, Les Mureaux, France). Height was measured to the nearest $0.5 \mathrm{~cm}$ on a standardized wall-mounted height board. Waist circumference (WC) was measured at the minimum circumference between the iliac crest and the rib cage at minimal respiration. Hip circumference was measured at the maximum protuberance of the buttocks. Using these data, waist-to-hip ratio (WHR) was calculated. BMI was defined as weight in kilograms divided by height in meters squared $\left(\mathrm{kg} / \mathrm{m}^{2}\right)$. Blood pressure was measured after at least 10 min rest in a sitting position.

\section{Bariatric Surgery}

All patients met the criteria detailed by the National Institutes of Health for selection of morbidly obese patients undergoing bariatric surgery [41]. Patients underwent restrictive bariatric surgery using one of three techniques: LAGB, LTGVP, or gastric bypass. All patients were operated by a single team.

\section{Laboratory Assays}

Blood samples were collected between 8:00 a.m. and 10:00 a.m. after10-12 h overnight fasting. Blood samples were centrifuged at $3,000 \times g$ for $10 \mathrm{~min}$. Plasma samples were stored at $-80^{\circ} \mathrm{C}$ until further analysis. Fasting plasma glucose was measured using the glucose oxidation method (Pars Azmoon, Tehran, Iran), and total cholesterol (TC), triglyceride (TG), and low-density lipoprotein cholesterol (LDL-C) were determined by enzyme colorimetric assay (Pars Azmoon) using an Eppendorf autoanalyzer (Eppendorf Corp., Hamburg, 
Hosseinzadeh-Attar et al.: Effect of Weight Reduction Following Bariatric Surgery on Serum Visfatin and Adiponectin Levels in Morbidly Obese Subjects

Table 1. Clinical and biochemical variables in morbid obese subjects before and after bariatric surgery $(n=35)$

\begin{tabular}{llll}
\hline & Before surgery & After surgery & p value \\
\hline Sex (F/M) & $26 / 9$ & $26 / 9$ & \\
Weight, kg & $128 \pm 20.7$ & $111.2 \pm 17.9$ & 0.000 \\
BMI, kg/m & $45 \pm 4.7$ & $39.2 \pm 4.6$ & 0.000 \\
WC, cm & $123.1 \pm 14.4$ & $111.3 \pm 12.9$ & 0.000 \\
WHR & $0.89 \pm 0.09$ & $0.87 \pm 0.09$ & 0.000 \\
\hline
\end{tabular}

Table 2. Biochemical variables in morbid obese subjects before and after bariatric surgery $(\mathrm{n}=$ 35)

\begin{tabular}{llll}
\hline & Before surgery & After surgery & p value \\
\hline Fasting glucose, mmol/l & $98 \pm 10.7$ & $94.2 \pm 7.7$ & 0.07 \\
HDL-C, mmol/l & $39.3 \pm 8.8$ & $37.3 \pm 6.7$ & 0.05 \\
LDL-C, mmol/l & $114.5 \pm 27.5$ & $105.2 \pm 24.7$ & 0.006 \\
TC, mmol/l & $190.8 \pm 38.9$ & $180.4 \pm 36.5$ & 0.08 \\
Adiponectin, ng/ml & $36.5 \pm 11$ & $41.3 \pm 11$ & 0.01 \\
Visfatin, ng/ml & $5 \pm 3.5$ & $3.4 \pm 3.2$ & 0.01 \\
\hline
\end{tabular}

Germany). High-density lipoprotein cholesterol (HDL-C) was measured using a precipitation-based method. The serum insulin level was assayed using an immunoradiometric method (Biosource Europe SA, Nivelles, Belgium). The insulin sensitivity was determined using the Homeostasis Model Assessment Index of insulin resistance (HOMA-IR) according to the following formula: HOMA-IR $=$ fasting insulin $(\mu \mathrm{U} / \mathrm{ml}) \times$ fasting glucose concentration (mmol/l) / 22.5 [42].

The serum concentrations of visfatin and adiponectin were determined by commercially available ELISA kits (Human Visfatin ELISA Kit and Human Adiponectin ELISA Kit; AdipoGen Pharmaceuticals Belmont, Seoul, South Korea). The intra- and inter-assay coefficient of variation of both kits was $<9.1 \%$ and $<5.5 \%$, respectively. The sensitivity of the visfatin and the adiponectin ELISA kit was 300 and $100 \mathrm{pg} / \mathrm{ml}$, respectively.

Statistical Analysis

The Kolmogorov-Smirnov test was applied to examine normal distribution of continuous variables. Continuous variables with normal distribution are presented as mean $\pm \mathrm{SD}$; for non-normal variables median (25th and 75th percentiles) were used. Differences between preoperative and postoperative data were tested by paired t-test or Wilcoxon sign rank test as appropriate. Correlations between changes of variables were explored using Pearson's or Spearman's correlation where appropriate. Comparisons of plasma levels of visfatin and adiponectin between three surgery methods were made using one-way analysis of variance (ANOVA). Statistical analyses were performed using the statistical package SPSS version 13.0 for Windows (SPSS Inc., Chicago, IL, USA). p values less than 0.05 were considered significant.

\section{Results}

Baseline Characteristics

35 morbidly obese patients, 26 women and 9 men, participated in the study. Their mean age was $33.5 \pm 9.1$ years and their mean BMI at baseline $45 \pm 4.7 \mathrm{~kg} / \mathrm{m}^{2} .14$ patients were submitted to LAGB, whereas LTGVP was performed in 14 patients; 7 patients underwent gastric bypass surgery. The anthropometric and biochemical characteristics of the patients before and after bariatric surgery are given in tables $1-3$. There were no differences in serum visfatin and adiponectin levels between patients submitted to LAGB, those submitted to LTGVP and those submitted to gastric bypass at baseline as well as after weight reduction. 
Hosseinzadeh-Attar et al.: Effect of Weight Reduction Following Bariatric Surgery on Serum Visfatin and Adiponectin Levels in Morbidly Obese Subjects

Table 3. Biochemical variables in morbid obese subjects before and after bariatric surgery $(\mathrm{n}=$ $35)^{\mathrm{a}}$

\begin{tabular}{llll}
\hline & Before surgery & After surgery & p value \\
\hline Fasting insulin, pmol/l & $13.1(9-20.7)$ & $11.7(10.1-15.0)$ & 0.15 \\
HOMA-IR & $3.1(2-4.6)$ & $2.7(2.3-3.5)$ & 0.09 \\
TG, mmol/l & $148(110-194)$ & $128(102-148)$ & 0.009 \\
\hline
\end{tabular}

${ }^{\mathrm{a}}$ All data are presented as median (25th and 75th percentile).

After bariatric surgery, a significant decrease in weight, BMI, WC, and WHR was shown (table 1). Serum visfatin as well as HDL-C, LDL-C, and TG levels also decreased, whereas adiponectin concentrations increased. No changes were observed in serum TG levels, fasting glucose concentrations, insulin concentrations, and HOMA-IR (tables 2, 3). Furthermore, we analyzed the changes of anthropometric and biochemical variables according to the type of surgery (LAGB, LTGVP, and gastric bypass). Reductions of weight, WC, and BMI were significant and similar in the three groups. The changes of insulin levels were significant only in those patients who had bypass surgery. However, in neither group, a significant change of HOMA-IR could be detected.

We did not observe any significant correlations between changes of circulating visfatin or adiponectin levels and changes of other metabolic variables. This remains true also after adjustment for age and sex.

\section{Discussion}

In the present study, we have shown that serum visfatin concentrations decreased and adiponectin concentrations in morbidly obese subjects increased significantly after weight reduction following bariatric surgery. Previous studies have reported inconsistent results as to the changes of serum visfatin and adiponectin levels after weight reduction. Obesity is considered as a low-grade inflammation, which is improved following weight loss $[6,31,43]$. Therefore, it is expected that weight reduction modulates secretion of adipokines from adipose tissue. Visfatin has been considered as a new pro-inflammatory adipokine [32]. Since the main site of visfatin secretion is VAT $[14,25]$, it was suggested that its plasma concentration is correlated with visceral obesity [14]. In recent years contradictory results have been published as to whether serum visfatin levels in obesity increase [23] or decrease [25], indicating that the association between obesity and visfatin is more complex than a simple dependency on body fat mass [44]. Also, the changes of serum visfatin concentrations following different kinds of weight reduction strategies in morbidly obese subjects, such as gastroplastic surgery [30], intestinal bypass [45], LAGB [46] and lifestyle modifications [47], were inconsistent. Some studies found decreased levels of circulating visfatin $[21,48]$ in line with our present results, but others reported increased plasma visfatin levels [30, 44, 45]. Moreover, some studies could not find any significant change of visfatin levels [31]. De Luis et al. [49] reported that visfatin concentrations did not change after 1 year of surgically induced weight loss. As demonstrated in our series, the type of bariatric surgery did not influence on changes of visfatin and adiponectin levels. The discrepant results could be explained by the a more complex relationship between visfatin and body fat level and its distribution; glucose homeostasis status and other factors such as iron metabolism [50], vascular endothelial function [51], genetic and race variation $[47,51]$, pattern of macronutrient intake, and dietary restriction of adipokin response $[47,52]$, may also influence visfatin metabolism. 
Hosseinzadeh-Attar et al.: Effect of Weight Reduction Following Bariatric Surgery on Serum Visfatin and Adiponectin Levels in Morbidly Obese Subjects

It has been shown that VAT is considerably decreased following weight loss [47] as demonstrated by reduction of WC $[44,53]$. A decreased amount of VAT following weight loss would suggest a reduction in visfatin concentrations after bariatric surgery. These results are in accordance with the hypothesis that visfatin is over-produced in obesity - possibly to compensate insulin resistance caused by increased adipose tissue. Following weight reduction, the need for this mechanism would be diminished [30, 48]. Berndt et al. [34] showed that plasma visfatin concentrations correlated with BMI, but not with WHR. This is why plasma visfatin is decreased following weight and BMI reduction. On the other hand, the inconsistent findings may be due to different inclusion criteria of patients, such as mean BMI, rate of weight reduction, and follow-up period [47]. Another potential explanation for short-time serum changes of adipokines following weight loss are rapid changes of adipokine production by the liver. Moschen et al. [46] indicated that serum concentrations and hepatic visfatin expression was reduced after bariatric surgery-induced weight loss. They concluded that weight loss in severely obese subjects enhances circulating levels and liver expression of the anti-inflammatory adipokine adiponectin while serum levels and/or liver expression of the pro-inflammatory adipocytokines such as visfatin are significantly reduced.

An additional reason for the discrepancy in results may be the use of C-terminal assays for detection of visfatin in some studies which was not reliable [54]; only an ELISA assay could detect full-length visfatin [54].

In the present studyk, we found significant changes of adiponectin levels following weight loss. Adiponectin has already been shown to have insulin-sensitizing and anti-inflammatory properties [55] and is known as a main mediator of glucose metabolism [56]. It is the only secretary protein of adipose tissue the expression of which is decreased or diminished in morbidly obese subjects [57].

An increase of adiponectin levels after weight reduction as a consequence of bariatric surgery procedures or dietary methods have been shown in several studies [58-60], being in accordance with our results. In contrast, other studies failed to observe such an increase [61]. The threshold of weight loss could be one of the possible reasons to promote adiponectin levels. It had been noted that a weight loss of $10 \%$ or more is required to induce an increase in plasma concentrations of adiponectin [57].

Many publications have evaluated long-term effects of bariatric surgery-induced weight reduction (6 months) on serum adipokine levels. In other words, the short-term effect of bariatric procedures on adipokines is unclear. We therefore planned to investigate shortterm effects of weight loss on visfatin and adiponectin levels after bariatric surgery. Swarbrick et al. [62] reported no changes of plasma adiponectin 1 month after bariatric surgery. They suggested that adiponectin-increasing effects of weight loss were obtained not until 3 months and with more pronounced weight loss [63]. However, we observed such changes after 6 weeks already. It seems that these changes were compatible with longer-term follow-up studies. This may help to clarify short-time metabolic adaptation induced by bariatric surgical procedures. Further studies should confirm these results.

In our series, the decrease of visfatin concentrations and the increase of adiponectin levels were accompanied by a decrease in BMI, WC, and WHR [21]. However, we did not observe any significant decreases of plasma insulin, glucose, and insulin sensitivity. Proinflammatory cytokines such as TNF- $\alpha$ and IL- 6 can inhibit the synthesis and secretion of adiponectin. Thus, decreasing TNF- $\alpha$ and IL- 6 level as a result of weight loss may contribute to the increase in adiponectin levels [64]. Therefore, reduction of adiposity may contribute to increasing adiponectin levels [35]. Some studies suggested that this relationship is mainly modulated by the degree of insulin resistance rather than adipose tissue accumulation or blood glucose levels $[65,66]$. Insulin is modulated by adiponectin via glucose and fatty acid metabolism [67], and adiponectin can improve insulin sensitivity in the liver [57, 
Hosseinzadeh-Attar et al.: Effect of Weight Reduction Following Bariatric Surgery on Serum Visfatin and Adiponectin Levels in Morbidly Obese Subjects

68].This means that insulin sensitivity is dependent on plasma adiponectin concentration $[12,38]$.

We could not find any significant association between changes of visfatin or adiponectin levels and changes of blood glucose or HOMA-IR. Small sample size might partly explain these findings. Another reason might be the normal fasting blood glucose before surgery. With a normal range of blood glucose, the need for increased visfatin as a compensatory mechanism to overcome hyperglycemia could be diminished. The increased level of visfatin before surgery therefore may be the result of a higher fat mass rather than of a compensatory mechanism. Another explanation would be that normal level of fasting blood glucose might be the result of increased visfatin levels to mimic insulin action. All these hypotheses could only explain in part the absence of any correlation between the changes of adipokines, like visfatin or adiponectin, and those of blood glucose and insulin sensitivity.

We also investigated whether or not the type of surgery has an influence on the changes of anthropometric variables, insulin levels, and HOMA-IR. Reductions of weight, WC and BMI were significant in the three surgical groups, but the changes of insulin levels were significant only in those patients who had bypass surgery as shown in other studies [35]. However, in neither group, a significant change of HOMA-IR could be detected.

We were not able to show any significant correlation between visfatin or adiponectin levels and anthropometric indices such as WC and BMI. It seems that these associations are more complex and not entirely understood thus far. Since patients with a narrow range of BMI (BMI $35-55 \mathrm{~kg} / \mathrm{m}^{2}$ ) were compared, we could not expect to find significant correlation between anthropometric indices and adipokine levels. In other words, with wider range of BMI the correlation would be more obvious. Furthermore, we could not find any significant correlation between the changes of circulating visfatin and plasma adiponectin concentrations, confirming results of other studies $[21,69,70]$. It has been suggested that counterregulatory adaptations in high-molecular-weight adiponectin and visfatin interaction might have an effect on glucose homeostasis and possibly on adipoinsular axis, contributing to the maintenance of normal glucose tolerance [22].

Our study has some limitations. The patients in our study only showed a narrow range of BMI and insulin resistance, and correlations might be more obvious if the ranges of BMI and insulin resistance are wider. Moreover, we did not measure high-molecular-weight adiponectin. Many studies have reported that the ratio of high-molecular-weight to total adiponectin determines or predicts insulin sensitivity more correctly than total adiponectin levels [22, 71].

In conclusion, weight reduction after bariatric surgery is associated with a significant decrease in circulating concentrations of the adipokine visfatin in morbidly obese subjects. In addition, weight loss in severely obese subjects increases anti-inflammatory adiponectin levels and modifies biochemical and anthropometric parameters. Further research is needed to clarify different aspects of adipokine action and their influence on the pathogenesis mechanisms of obesity and insulin-resistant disorders.

\section{Acknowledgements}

We gratefully thank all persons who participated in this study. This study was supported by Tehran University of Medical Sciences \& Health Services and Endocrine and Metabolism Research Center (EMRC) Tehran, Iran, grants.

\section{Disclosure Statement}

All contributing authors declare that they have no conflicts of interest. 
Hosseinzadeh-Attar et al.: Effect of Weight Reduction Following Bariatric Surgery on Serum Visfatin and Adiponectin Levels in Morbidly Obese Subjects

\section{References}

1 Pickup J, Crook M: Is type II diabetes mellitus a disease of the innate immune system? Diabetologia 1998;41: 1241-1248.

-2 Grundy SM, Brewer HB Jr, Cleeman JI, Smith SC Jr, Lenfant C: Definition of metabolic syndrome report of the National Heart, Lung, and Blood Institute/American Heart Association Conference on scientific issues related to definition. Circulation 2004;109:433-438.

3 Trujillo ME, Scherer PE: Adipose tissue-derived factors: impact on health and disease. Endocr Rev 2006;27: 762-778.

4 Ronti T, Lupattelli G, Mannarino E: The endocrine function of adipose tissue: an update. Clin Endocrinol 2006; 64:355-365.

5 Shah M, Simha V, Garg A: Long-term impact of bariatric surgery on body weight, comorbidities, and nutritional status. J Clin Endocrinol Metab 2006;91:4223-4231.

6 Buchwald H, Avidor Y, Braunwald E, Jensen MD, Pories W, Fahrbach K, et al: Bariatric surgery. JAMA 2004; 292:1724-1737.

7 Sjöström L, Narbro K, Sjöström CD, Karason K, Larsson B, Wedel H, et al: Effects of bariatric surgery on mortality in Swedish obese subjects. N Engl J Med 2007;357:741-752.

8 Ahima RS, Flier JS: Adipose tissue as an endocrine organ. Trends Endocrinol Metab 2000;11:327-332.

-9 Scherer PE: Adipose tissue. Diabetes 2006;55:1537-1545.

10 Trayhurn P: Endocrine and signalling role of adipose tissue: new perspectives on fat. Acta Physiol Scand 2005; 184:285-293.

-11 Maury E, Brichard S: Adipokine dysregulation, adipose tissue inflammation and metabolic syndrome. Mol Cell Endocrinol 2010;314:1-16.

12 Faraj M, Havel PJ, Phélis S, Blank D, Sniderman AD, Cianflone K: Plasma acylation-stimulating protein, adiponectin, leptin, and ghrelin before and after weight loss induced by gastric bypass surgery in morbidly obese subjects. J Clin Endocrinol Metab 2003;88:1594-1602.

13 Ouchi N, Parker JL, Lugus JJ, Walsh K: Adipokines in inflammation and metabolic disease. Nat Rev Immunol 2011;11:85-97.

14 Fukuhara A, Matsuda M, Nishizawa M, Segawa K, Tanaka M, Kishimoto K, et al: Visfatin: a protein secreted by visceral fat that mimics the effects of insulin. Science 2005;307:426-430. Retraction in Science 2007;318:565.

15 Revollo JR, Grimm AA, Imai S: The regulation of nicotinamide adenine dinucleotide biosynthesis by Nampt/ PBEF/visfatin in mammals. Curr Opin Gastroenterol 2007;23:164-170.

16 Busso N, Karababa M, Nobile M, Rolaz A, Van Gool F, Galli M, et al: Pharmacological inhibition of nicotinamide phosphoribosyltransferase/visfatin enzymatic activity identifies a new inflammatory pathway linked to NAD. PLoS One 2008;3:e2267.

17 Guzik T, Mangalat D, Korbut R: Adipocytokines - novel link between inflammation? J Physiol Pharmacol 2006; 57:505-528.

18 Moschen AR, Kaser A, Enrich B, Mosheimer B, Theurl M, Niederegger H, et al: Visfatin, an adipocytokine with proinflammatory and immunomodulating properties. J Immunol 2007;178:1748-1758.

19 Vázquez-Vela MEF, Torres N, Tovar AR: White adipose tissue as endocrine organ and its role in obesity. Arch Med Res 2008;39:715-728.

20 Varma V, Yao-Borengasser A, Rasouli N, Bodles AM, Phanavanh B, Lee MJ, et al: Human visfatin expression: relationship to insulin sensitivity, intramyocellular lipids, and inflammation. J Clin Endocrinol Metab 2007;92: 666-672.

-21 Haider DG, Schindler K, Schaller G, Prager G, Wolzt M, Ludvik B: Increased plasma visfatin concentrations in morbidly obese subjects are reduced after gastric banding. J Clin Endocrinol Metab 2006;91:1578-1581.

-22 Ünlütürk U, Harmancı A, Yıldız BO, Bayraktar M: Dynamics of Nampt/visfatin and high molecular weight adiponectin in response to oral glucose load in obese and lean women. Clin Endocrinol 2010;72:469-474.

-23 Zahorska-Markiewicz B, Olszanecka-Glinianowicz M, Janowska J, Kocelak P, Semik-Grabarczyk E, Holecki M, et al: Serum concentration of visfatin in obese women. Metabolism 2007;56:1131-1134.

24 Davutoglu M, Ozkaya M, Guler E, Garipardic M, Gursoy H, Karabiber H, et al: Plasma visfatin concentrations in childhood obesity: relationships to insulin resistance and anthropometric indices. Swiss Med Weekly 2010; 139:22.

25 Pagano C, Pilon C, Olivieri M, Mason P, Fabris R, Serra R, et al: Reduced plasma visfatin/pre-B cell colonyenhancing factor in obesity is not related to insulin resistance in humans. J Clin Endocrinol Metab 2006;91: 3165-3170.

26 Mercader J, Granados N, Caimari A, Oliver P, Bonet M, Palou A: Retinol-binding protein 4 and nicotinamide phosphoribosyltransferase/visfatin in rat obesity models. Horm Metab Res 2008;40:467-472.

27 Catalán V, Gómez-Ambrosi J, Rodríguez A, Ramírez B, Silva C, Rotellar F, et al: Association of increased visfatin/ PBEF/NAMPT circulating concentrations and gene expression levels in peripheral blood cells with lipid metabolism and fatty liver in human morbid obesity. Nutr Metab Cardiovasc Dis 2011;21:245-253.

28 Klöting N, Klöting I: Visfatin: gene expression in isolated adipocytes and sequence analysis in obese WOKW rats compared with lean control rats. Biochem Biophys Res Commun 2005;332:1070-1072.

29 Stofkova A, Skurlova M, Kiss A, Zelezna B, Zorad S, Jurcovicova J: Activation of hypothalamic NPY, AgRP, MC4R, AND IL-6 mRNA levels in young Lewis rats with early-life diet-induced obesity. Endocr Regul 2009;43:99-106. 
Hosseinzadeh-Attar et al.: Effect of Weight Reduction Following Bariatric Surgery on Serum Visfatin and Adiponectin Levels in Morbidly Obese Subjects

-30 Krzyzanowska K, Mittermayer F, Krugluger W, Kopp HP, Schernthaner G: Increase in visfatin after weight loss induced by gastroplastic surgery. Obesity (Silver Spring) 2006;14:1886-1889.

-31 Manco M, Fernandez-Real JM, Equitani F, Vendrell J, Mora MEV, Nanni G, et al: Effect of massive weight loss on inflammatory adipocytokines and the innate immune system in morbidly obese women. J Clin Endocrinol Metab 2007;92:483-490.

-32 Stofkova A: Resistin and visfatin: regulators of insulin sensitivity, inflammation and immunity. Endocr Regul $2010 ; 44: 25-36$

33 Kovacikova M, Vitkova M, Klimcáková E, Polak J, Hejnová J, Bajzova M, et al: Visfatin expression in subcutaneous adipose tissue of pre-menopausal women: relation to hormones and weight reduction. Eur J Clin Invest 2008;38:516-522.

34 Berndt J, Klöting N, Kralisch S, Kovacs P, Fasshauer M, Schön MR, et al: Plasma visfatin concentrations and fat depot-specific mRNA expression in humans. Diabetes 2005;54:2911-2916.

-35 Butner KL, Nickols-Richardson SM, Clark SF, Ramp WK, Herbert WG: A review of weight loss following Rouxen-Y gastric bypass vs restrictive bariatric surgery: impact on adiponectin and insulin. Obes Surg 2010;20: 559-568.

-36 Tilg H, Hotamisligil GS: Nonalcoholic fatty liver disease: cytokine-adipokine interplay and regulation of insulin resistance. Gastroenterology 2006;131:934-945.

-37 Guldstrand M, Ahrén B, Adamson U: Improved $\beta$-cell function after standardized weight reduction in severely obese subjects. Am J Physiol Endocrinol Metab 2003;284:E557-E565.

-38 Tschritter O, Fritsche A, Thamer C, Haap M, Shirkavand F, Rahe S, et al: Plasma adiponectin concentrations predict insulin sensitivity of both glucose and lipid metabolism. Diabetes 2003;52:239-243.

-39 Stofkova A: Leptin and adiponectin: from energy and metabolic dysbalance to inflammation and autoimmunity. Endocr Regul 2009;43:157-168.

40 Ballantyne GH, Gumbs A, Modlin IM: Changes in insulin resistance following bariatric surgery and the adipoinsular axis: role of the adipocytokines, leptin, adiponectin and resistin. Obes Surg 2005;15:692-699.

-41 Yermilov I, McGory ML, Shekelle PW, Ko CY, Maggard MA: Appropriateness criteria for bariatric surgery: beyond the NIH guidelines. Obesity (Silver Spring). 2009;17:1521-1577.

42 Matthews D, Hosker J, Rudenski A, Naylor B, Treacher D, Turner R: Homeostasis model assessment: insulin resistance and $\beta$-cell function from fasting plasma glucose and insulin concentrations in man. Diabetologia $1985 ; 28: 412-419$.

-43 Cottam DR, Mattar SG, Barinas-Mitchell E, Eid G, Kuller L, Kelley DE, et al: The chronic inflammatory hypothesis for the morbidity associated with morbid obesity: implications and effects of weight loss. Obes Surg 2004;14: 589-600.

-44 Botella-Carretero JI, Luque-Ramírez M, Álvarez-Blasco F, Peromingo R, San Millán JL, Escobar-Morreale HF: The increase in serum visfatin after bariatric surgery in morbidly obese women is modulated by weight loss, waist circumference, and presence or absence of diabetes before surgery. Obes Surg 2008;18: 1000-1006.

-45 García-Fuentes E, García-Almeida JM, García-Arnés J, García-Serrano S, Rivas-Marín J, Gallego-Perales JL, et al: Plasma visfatin concentrations in severely obese subjects are increased after intestinal bypass. Obesity (Silver Spring) 2007;15:2391-2395.

46 Moschen AR, Molnar C, Wolf AM, Weiss H, Graziadei I, Kaser S, et al: Effects of weight loss induced by bariatric surgery on hepatic adipocytokine expression. J Hepatol 2009;51:765-777.

47 de Luis DA, Gonzalez Sagrado M, Conde R, Aller R, Izaola 0, Romero E: Effect of a hypocaloric diet on serum visfatin in obese non-diabetic patients. Nutrition 2008;24:517-521.

48 Swarbrick M, Stanhope K, Austrheim-Smith I, Van Loan M, Ali M, Wolfe B, et al: Longitudinal changes in pancreatic and adipocyte hormones following Roux-en-Y gastric bypass surgery. Diabetologia 2008;51:19011911.

49 de Luis DA, Izaola 0, Conde R, Primo D, Sagrado MG, Aller R: Visfatin levels in female, morbid, nondiabetic obese patients after biliopancreatic diversion surgery. Surg Obes Relat Dis 2011;7:195-198.

-50 Fernández-Real JM, Moreno JM, Chico B, López-Bermejo A, Ricart W: Circulating visfatin is associated with parameters of iron metabolism in subjects with altered glucose tolerance. Diabetes Care 2007;30:616-621.

51 Takebayashi K, Suetsugu M, Wakabayashi S, Aso Y, Inukai T: Association between plasma visfatin and vascular endothelial function in patients with type 2 diabetes mellitus. Metabolism 2007;56:451-458.

$\checkmark 52$ Golpaie A, Tajik N, Masoudkabir F, Karbaschian Z, Talebpour M, Hoseini M, et al: Short-term effect of weight loss through restrictive bariatric surgery on serum levels of vaspin in morbidly obese subjects. Eur Cytokine Netw 2011;22:181-186.

53 Pontiroli AE, Pizzocri P, Librenti MC, Vedani P, Marchi M, Cucchi E, et al: Laparoscopic adjustable gastric banding for the treatment of morbid (grade 3) obesity and its metabolic complications: a three-year study. J Clin Endocrinol Metab 2002;87:3555-3561.

54 Körner A, Garten A, Blüher M, Tauscher R, Kratzsch J, Kiess W: Molecular characteristics of serum visfatin and differential detection by immunoassays. J Clin Endocrinol Metab 2007;92:4783-4791.

55 Bełtowski J: Adiponectin and resistin - new hormones of white adipose tissue. Med Sci Monit 2003;9:RA5561.

-56 Yamauchi T, Kamon J, Minokoshi Y, Ito Y, Waki H, Uchida S, et al: Adiponectin stimulates glucose utilization and fatty-acid oxidation by activating AMP-activated protein kinase. Nat Med 2002;8:1288-1295. 
Hosseinzadeh-Attar et al.: Effect of Weight Reduction Following Bariatric Surgery on Serum Visfatin and Adiponectin Levels in Morbidly Obese Subjects

57 de Carvalho CP, Marin DM, de Souza AL, Pareja JC, Chaim EA, de Barros Mazon S, et al: GLP-1 and adiponectin: effect of weight loss after dietary restriction and gastric bypass in morbidly obese patients with normal and abnormal glucose metabolism. Obes Surg 2009;19:313-320.

-58 Kotidis EV, Koliakos GG, Baltzopoulos VG, Ioannidis KN, Yovos JG, Papavramidis ST: Serum ghrelin, leptin and adiponectin levels before and after weight loss: comparison of three methods of treatment - a prospective study. Obes Surg 2006;16:1425-1432.

59 Mari A, Manco M, Guidone C, Nanni G, Castagneto M, Mingrone G, et al: Restoration of normal glucose tolerance in severely obese patients after bilio-pancreatic diversion: role of insulin sensitivity and beta cell function. Diabetologia 2006;49:2136-2143.

60 Esposito K, Pontillo A, Di Palo C, Giugliano G, Masella M, Marfella R, et al: Effect of weight loss and lifestyle changes on vascular inflammatory markers in obese women. JAMA 2003;289:1799-1804.

61 Abbasi F, Lamendola C, McLaughlin T, Hayden J, Reaven GM, Reaven PD: Plasma adiponectin concentrations do not increase in association with moderate weight loss in insulin-resistant, obese women. Metabolism 2004; 53:280-283.

62 Swarbrick M, Austrheim-Smith I, Stanhope K, Van Loan M, Ali M, Wolfe B, et al: Circulating concentrations of high-molecular-weight adiponectin are increased following Roux-en-Y gastric bypass surgery. Diabetologia 2006;49:2552-2558

63 Linscheid P, Christ-Crain M, Stoeckli R, Reusch C, Lutz T, Müller B, et al: Increase in high molecular weight adiponectin by bariatric surgery-induced weight loss. Diabetes Obes Metab 2008;10:1266-1270.

64 Vilarrasa N, Vendrell J, Sánchez-Santos R, Broch M, Megia A, Masdevall C, et al: Effect of weight loss induced by gastric bypass on proinflammatory interleukin-18, soluble tumour necrosis factor- $\alpha$ receptors, C-reactive protein and adiponectin in morbidly obese patients. Clin Endocrinol 2007;67:679-686.

65 Poitou C, Lacorte JM, Coupaye M, Bertrais S, Bedel JF, Lafon N, et al: Relationship between single nucleotide polymorphisms in leptin, IL6 and adiponectin genes and their circulating product in morbidly obese subjects before and after gastric banding surgery. Obes Surg 2005;15:11-23.

-66 Weyer C, Funahashi T, Tanaka S, Hotta K, Matsuzawa Y, Pratley RE, et al: Hypoadiponectinemia in obesity and type 2 diabetes: close association with insulin resistance and hyperinsulinemia. J Clin Endocrinol Metab 2001; 86:1930-1935.

67 Antuna-Puente B, Feve B, Fellahi S, Bastard JP: Adipokines: the missing link between insulin resistance and obesity. Diabetes Metab 2008;34:2-11.

-68 Esposito K, Giugliano G, Scuderi N, Giugliano D: Role of adipokines in the obesity-inflammation relationship: the effect of fat removal. Plast Reconstr Surg 2006;118:1048-1057.

69 Dogru T, Sonmez A, Tasci I, Bozoglu E, Yilmaz MI, Genc H, et al: Plasma visfatin levels in patients with newly diagnosed and untreated type 2 diabetes mellitus and impaired glucose tolerance. Diabetes Res Clin Pract 2007;76:24-29.

70 Retnakaran R, Youn BS, Liu Y, Hanley AJG, Lee NS, Park JW, et al: Correlation of circulating full-length visfatin (PBEF/NAMPT) with metabolic parameters in subjects with and without diabetes: a cross-sectional study. Clin Endocrinol 2008;69:885-893.

71 Benedix F, Westphal S, Patschke R, Granowski D, Luley C, Lippert H, et al: Weight loss and changes in salivary ghrelin and adiponectin: comparison between sleeve gastrectomy and Roux-en-Y gastric bypass and gastric banding. Obes Surg 2011;21:616-624. 